\title{
Электретный эффект в композитах полимер-сегнетопьезокерамика с различной электроотрицательностью полимерной матрицы и катионов пьезофазы
}

\author{
(C) М.А. Курбанов, И.С. Рамазанова, З.А. Дадашев, У.В. Юсифова, Г.Х. Гусейнова, \\ К.К. Азизова, И.А. Фараджзаде \\ Институт физики Национальной академии наук Азербайджана, \\ AZ-1143 Баку, Азербайджан \\ E-mail: mKurbanov@physics.ab.az
}

(Получена 7 марта 2017г. Принята к печати 20 марта 2017г.)

\begin{abstract}
Определено влияние электроотрицательности фаз, регулируемой кристаллизацией композита в условиях действия плазмы электрического разряда и ковалентностью катионов пьезофазы, на механизм формирования стабильного электретного эффекта. Выявлены особенности формирования электретного эффекта в композитах на основе полиолефинов (ПЭВП, ПП), фторсодержащих полимеров (Ф42) и сегнетопьезоэлектрической керамики семейства цирконата-титаната свинца $\left(\mathrm{Pb}(\mathrm{Zr}, \mathrm{Ti}) \mathrm{O}_{3}\right)$, кристаллизованных в условиях действия плазмы электрического разряда. Предложена физическая модель электретных композитов, учитывающая роль гомо- и гетерозарядов, созданных в композите, путем диспергирования ее пьезокерамическими частицами различной структуры - ромбоэдрической, тетрагональной, гетерогенной.
\end{abstract}

DOI: 10.21883/FTP.2018.01.45321.8490

\section{1. Введение}

В настоящее время существует в основном четыре направления в области создания электретных и пьезоэлектрических материалов на основе твердых диэлектриков и полупроводников. Одно из них связано с синтезом все новых и новых пьезокерамических материалов на основе титаната бария и многокомпонентных сегнетоактивных растворов семейства цирконата-титаната свинца (ЦТС) [1-4]. Второе базируется на синтезе температуроустойчивых полярных и неполярных полимеров, проявляющих электретные свойства [5-8]. Новая возможность открывает третье направление, связанное с созданием различных электретных композитных материалов на основе полярных и неполярных полимеров (матрица) и микроразмерных сегнетопьезокерамических или полупроводниковых частиц (диспергатор) [9-16]. В последнее время наряду с третьим направлением интенсивно развивается четвертое направление, связанное с созданием матричных наноструктурированных электретных композитов [17-22]. Многоплановость нанотехнологий и особые свойства наноразмерной неорганической фазы и полимерной матрицы, окружающей наночастицы, делают нанокомпозиты весьма важными материалами различных назначений $[19,21,22]$. Заметное уменьшение подвижности макромолекул в объеме, в котором распространяется действие микро- и наноразмерных частиц, заметно расширяет предел температурной стабильности электретных характеристик указанных композитов. Отметим, что на пути создания технологии получения электретных композитов с наноразмерной фазой стоит нерешенная и достаточно сложная задача получения наноразмерных сегнетопьезоэлектрических частиц из существующих эффективных сегнетопьезоке- рамик различных структур и их иммобилизация [21,22]. Поэтому в настоящее время более эффективным направлением в разработке активных электретных композитов пока является получение композитных SMART материалов с микроразмерной сегнетоэлектрической фазой $[15,16,18,22,23]$.

Цель данной работы заключается в определении влияния электроотрицательности фаз, регулируемой кристаллизацией композита в условиях действия плазмы электрического разряда и ковалентностью катионов пьезофазы, на механизм формирования стабильного электретного эффекта.

Указанные вопросы решены путем разработки технологии получения композитных пьезоэлектриков и электретов с глубокими центрами захвата зарядов путем кристаллизации их в условиях одновременного воздействия плазмы барьерного электрического разряда и температуры, а также создания физической модели композитов, учитывающей роль гомо- и гетерозарядов, созданных в композите, путем диспергирования ее пьезокерамическими частицами различной структуры ромбоэдрической, тетрагональной, гетерогенной.

\section{2. Методика эксперимента}

Рассмотрены матричные композиты (тип 0-3) на основе пьезокерамики семействацирконата-титаната свинца типа $\mathrm{PbTiO}_{3}-\mathrm{PbZrO}_{3}-\mathrm{PbNb}_{2 / 3} \mathrm{Zn}_{1 / 3} \mathrm{O}_{3}-\mathrm{PbNb}_{2 / 3} \mathrm{Mn}_{1 / 3} \mathrm{O}_{3}$, полиолефинов (ПЭВП, ПП) и галогенсодержащих полимеров (Ф-42) [4,6,15]. Выбор карбоцепных полимеров обусловлен тем, что они характеризуются высокой воспроизводимостью по составу, строению и физикохимическим свойствам. Композитные элементы получены методом горячего прессования. Из гомогенной меха- 
нической смеси порошков получен электретный элемент в виде дисков и цилиндров различных геометрических размеров. Для композитов на основе галогенсодержащих полимеров и полиолефинов области температур и давления получения соответственно составляли $(420-550) \mathrm{K}$ и (30-100) МПа. Время прессования после достижения выбранной температуры равно 0.5 ч.

Поляризация образцов композитов проводилась в воздухе при приложении постоянного электрического поля напряженностью $\left(E_{\text {pol }}\right)$ от 1 до $6 \mathrm{MB} /$ м при температуре $\left(T_{\mathrm{pol}}\right) 353-450 \mathrm{~K}$ и времени $\left(t_{\mathrm{pol}}\right)$ поляризации 0.5 ч. Методика исследования электретного эффекта связана с определением поверхностной плотности заряда, знака и длительности сохранения его во времени $[5,8,12]$. Поверхностная эффективная плотность заряда $\left(Q_{\text {eff }}\right)$ и время релаксации заряда $(\tau)$ определены на основе метода индукции с компенсацией электретной разности потенциалов $U_{\text {dif }}$ [7]. Измерительный электрод (ИЭ), на который индуцируется заряд от заряженной поврехности электрета, периодически экранируется с помощью четырехлопастной крыльчатки, вращающейся в зазоре между электретом и электродом. Модификация композитных электретных элементов осуществлялась в условиях действия плазмы электрического разряда в воздухе, ограниченного диэлектриками (частичный разряд) $[8,12,14,16]$. Методики модификации фаз композитов в условиях действия плазмы электрических разрядов подробно описаны в $[8,12,14]$. Для осуществления модификации композитов в условиях действия плазмы электрического разряда нами были использованы следующие приборы: источник высокого напряжения УПУ-10 ( $U_{\text {out }}=10$ кВТ $)$; двухкоординатный самописец сигналов типа Н 307/1; осциллограф двухканальный. C1-176; электрометрический усилитель типа У5-11 и вольтметр В7-57.1. Выбор частичного разряда обусловлен возможностью осуществления равномерной обработки поверхностей частиц полимера и наполнителя (рис. $1, a-d)$. Электрический разряд возникает в системе металл-диэлектрик-газовая среда-исследуемый композит-металл. Интенсивность разряда варьировалась изменением амплитуды приложенного к испытательной ячейке напряжения частотой 50 Гц. Время обработки изменялась до 2 ч. Мощность разряда за период синусоидального напряжения определялась методом вольт-кулоновой характеристики [24]. Энергия отдельных частичных разрядов определялась по оптической картине, полученной электроннооптическим преобразователем (рис. 1, a) [25].

\section{3. Экспериментальные результаты и их обсуждение}

На рис. 1 приведены оптические (рис. 1,a), электрические (рис. $1, b)$ картины развития разряда в системе металл-диэлектрик-газовая среда- исследуемый композит-металл (МДГКМ). Как видно из рисунка,
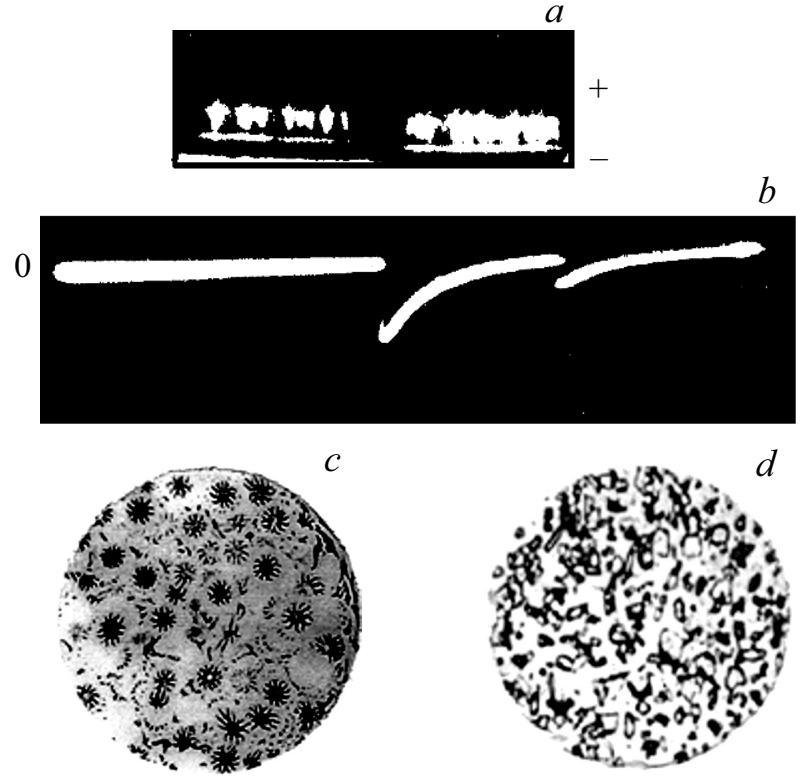

Рис. 1. Разновидности картин электрического разряда в системе металл-диэлектрик-газ-композит-металл: $a$ - оптическая картина (ЭОП-грамма); $b$ - электрическая (осциллограмма) картина; $c$ - электрографическая картина поверхности электретного композита, подвергнутого действию электричекого разряда; $d-$ микроскопическая картина поверхности электретного композита, подвергнутого действию электрического разряда.

электрический разряд возникает в виде серии дискретных во времени и в пространстве частичных разрядов (рис. $1, a)$. Каждая серия микроразрядов соответствует одному импульсу тока разряда на осциллограмме (рис. $1, b)$. В приведенной картине импульсы тока регистрированы за 1/4 периода приложенного синусоидального напряжения. Запуск осциллографа для регистрации импульсов тока разряда осуществлен при переходе через нуль приложенного синусоидального напряжения (рис. $1, b)$. На рис. 1, с приведена электрографическая картина контакта поверхности композита с дискретными каналами разряда. После электрографической обработки получаем картину распределения микроразрядов по всей площади исследуемого композита. Эта картина также дает информацию о наличии зарядов, образовавшихся в местах контакта микроразряд - композит. Указанные оптические, электрические и электрографические картины дают также информацию о достаточно равномерной модификации композитных элементов в условиях действия частичных разрядов в газовом зазоре, ограниченном пьезоэлектрическими композитами.

На рис. $1, d$ приведена микроскопическая картина поверхности пьезоэлемента, прошедшего разрядовую модификацию. Оптическая картина развития разряда получена применением электронно-оптического преобразователя, разработанного академиком Е.К. Завойским и его школой [25]. На рис. 2 сопоставлены результаты 


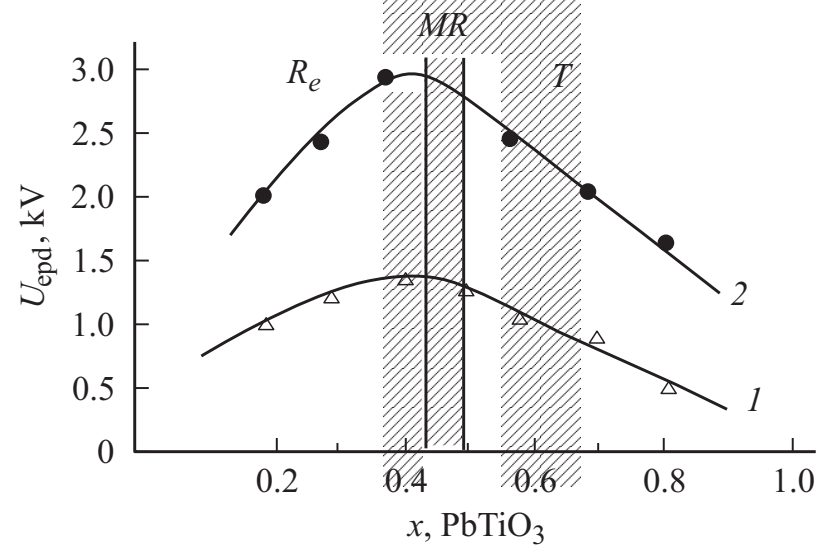

Рис. 2. Изменение $U_{\text {epo }}$ композита ПП- $\mathrm{Pb}\left(\mathrm{Ti}_{x} \mathrm{Zr}_{1-x}\right) \mathrm{O}_{3}$ в зависимости от параметра $(X)$ состава $\mathrm{Pb}\left(\mathrm{Ti}_{x} \mathrm{Zr}_{1-x}\right) \mathrm{O}_{3}$; $x=0.2-0.8: 1$ - электротермополяризованные композиты; 2 - предварительно плазмокристаллизованные, а затем электротермополяризованные композиты.

исследования электретной разности потенциалов $U_{\text {epd }}$ композитов в зависимости от структуры пьезофазы (кривые 1 и 2). Кривая 1 на рисунке показывает зависимость $U_{\text {epd }}$ от концентрации $\mathrm{PbTiO}_{3}$ для электротермополяризованных композитов, кривая 2 - для предварительно плазмокристаллизованных, а затем электротермополяризованных композитов. Из рисунка видно, что закономерность изменения электретной разности

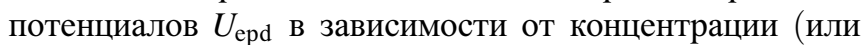
состава) твердого раствора $\mathrm{PbTiO}_{3}$ практически одинакова, но численные значения $U_{\text {epd }}$ для каждого состава заметно отличаются, т. е. плазмокристаллизованные электретные композиты обладают высоким значением $U_{\text {epd }}$ (или электретного заряда). Зависимость электретной разности потенциалов от концентрации $\mathrm{PbTiO}_{3}$ пьезофазы имеет экстремальный характер, при этом максимум этой зависимости находится в ромбоэдрической области вблизи морфотропной. Экстремальный характер зависимости $U_{\text {epd }}$ от концентрации $\mathrm{PbTiO}_{3}$ пьезофазы семейства цирконата-титаната свинца, по-видимому, связан с отличием сегнетожесткости и сегнетомягкости используемой пьезокерамики. Кроме этого, большое значение имеет и электроотрицательность катионов пьезокерамик ромбоэдрической структуры. Немаловажным фактором является и наличие локального механического напряжения, возникающего при поляризации композитов. Механический фактор более ярко выражен в керамиках тетрагональной структуры [4] и, следовательно, сопровождается снижением величины электретной разности потенциалов. Показателем увеличения электроотрицательности полимерной матрицы в результате ее кристаллизации в условиях действия плазмы электрического разряда является появление в ИК спектре следующих кислородосодержащих групп (рис. 3): C-O, C-O-C, $\mathrm{OH}, \mathrm{CH}_{2}$. Аналогичные результаты были получены и для композитов на основе фторсодержащих полимеров, в частности ПВДФ [16]. Приведенные результаты показывают, что в результате плазменной модификации происходит сильное окисление полимерной цепи, т.е. макромолекулы приобретают электроотрицательность и некий дипольный момент. Окисленные центры служат ловушками для инжектированных зарядов при электротермополяризации. Высокая электроотрицательность кислородосодержащих групп создает глубокие ловушки для носителей заряда на границе раздела фаз. Кроме указанных эффектов, происходит сшивание макромолекул через кислородные мостики, что сопровождается в свою очередь уменьшением подвижности макромолекул и степени свободы. Приобретение электроотрицательности и дипольного момента макромолекулой также приводит к увеличению межмолекулярных взаимодействий. Кроме межмолекулярных взаимодействий следует отметить, что окисление макромолекул сопровождается ростом межфазных взаимодействий. Использование фторсодержащих полимеров в качестве полимерной матрицы имеет особое значение, так как фторсодержащий полимер более чувствителен к плазменной модификации. Причиной этого явления является высокая электроотрицательность атомов фтора [12]. В задаче, поставленной нами, фигурирует вопрос о влиянии плазменной кристаллизации на микроскопические параметры пьезофазы и макроскопические параметры композита в целом. В качестве микроскопических параметров пьезофазы нами использован $\delta$ (однородный параметр спонтан-

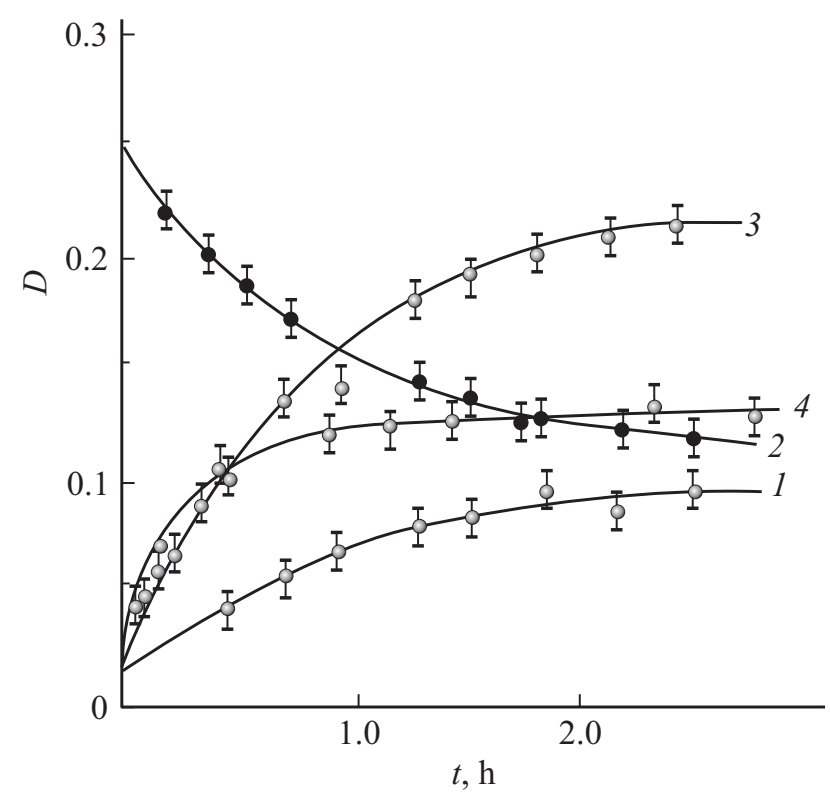

Рис. 3. Изменение оптической плотности инфракрасного поглощения полипропилена (ПП), подвергнутого действию электрического разряда в зависимости от времени обработки: $1-3200 \mathrm{~cm}^{-1}-\mathrm{OH} ; 2-4327 \mathrm{~cm}^{-1}-\mathrm{CH}_{2}$; $3-1720 \mathrm{~cm}^{-1}-\mathrm{C}=\mathrm{O} ; 4-1278 \mathrm{~cm}^{-1}-\mathrm{C}-\mathrm{O}-\mathrm{C}$; группы. Толщина воздушного включения, где возникают электрический разряд $d=4$ мм. Напряжение, приложенное к плазматрону $U=20 \kappa \mathrm{B}$. 


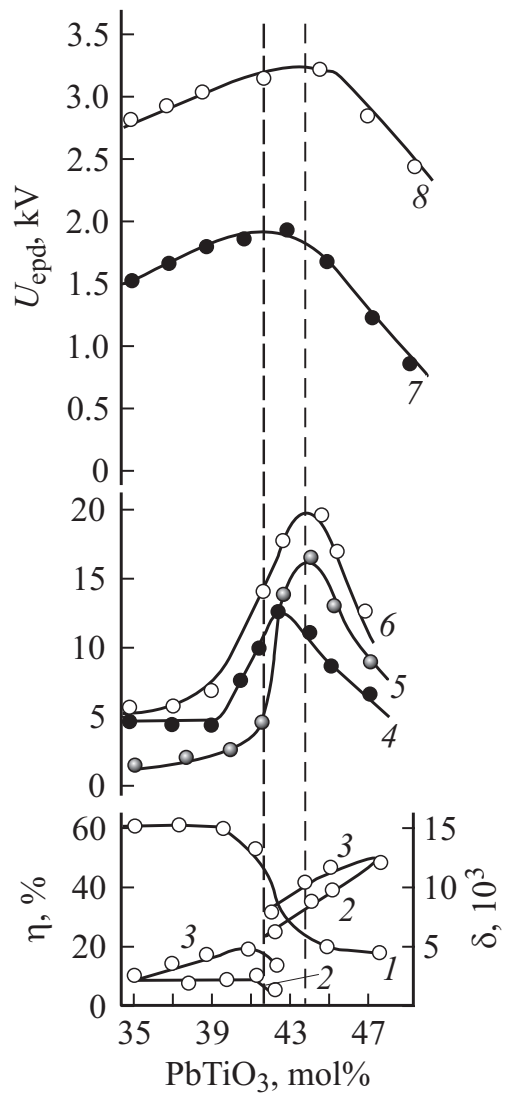

Рис. 4. Зависимости $\eta(1), \delta(2)$ до (2) и после поляризации $(3), \varepsilon / \varepsilon_{0}$ (неполяризованная -4$), \varepsilon_{33}^{T} / \varepsilon_{0}$ (поляризованная - 5) пьезофазы от содержания $\mathrm{PbTiO}_{3}$ в ней, т.е. в системе ЦТС-21, $\varepsilon_{k}^{T} / \varepsilon_{0}$ (поляризованный при температуре $T_{p d}$ больше чем температура Кюри $T_{c}=453 \mathrm{~K}-6$ ) пьезофазы от содержания $\mathrm{PbTiO}_{3}$ в ней, т. е. в системе $\mathrm{PbTiO}_{3}-\mathrm{PbZrO}_{3}$; зависимость $U_{e p d}$ композита ПП $+5 \%$ об. ЦТС-21 (7) от содержания $\mathrm{PbTiO}_{3}$ пьезофазы $\mathrm{PbTiO}_{3}-\mathrm{PbZrO}_{3}$; зависимость $U_{\text {epd }}$ композита ПП $+5 \%$ об. ЦТС-21 от содержания компонента $\mathrm{PbTiO}_{3}$ пьезофазы $\mathrm{PbTiO}_{3}-\mathrm{PbZrO}_{3}$ для предварительно плазмокристаллизованных образцов ПП $+5 \%$ об. ЦТС-21 (8). Размер пьезочастиц 150 мкм, $E_{p o l}=2 \mathrm{MB} / \mathrm{M}, T_{p o l}=413 \mathrm{~K}, t_{p o l}=0.5$ ч. Композит ПП $+5 \%$ об. ЦТС- 21 .

ной деформации) и $\eta$ (степень доменных переориентаций) [4]. В качестве макроскопических параметров композита использованы параметры $U_{\text {epd }}, \varepsilon, Q_{\text {eff. }}$ На рис. 4 приведены зависимости $\varepsilon, \delta, \eta$ от концентрации $\mathrm{PbTiO}_{3}$ в пьезокерамике ЦТС-21. Там же приведена зависимость $U_{\text {epd }}$ композита ПП $+5 \% \mathrm{PbTiO}_{3}-\mathrm{PbZrO}_{3}$ от концентрации $\mathrm{PbTiO}_{3}$ пьезофазы. Видно, что максимальное значение этой зависимости $U_{\text {epd }}$ находится в середине морфотропной области, где структура пьезофазы является гетерогенной $\left(R_{e}+T\right)$. У плазмокристаллизованных композитов максимум $U_{\text {epd }}$ больше по величине и максимум зависимости $U_{\text {epd }}$ от концентрации $\mathrm{PbTiO}_{3}$ находится в тетрагональной области. Видно, что максимум $\varepsilon_{33}^{T}$ имеет место в морфотропной области и смещен к границе тетрагонального состава.
На рисунке сопоставлены величины $\varepsilon / \varepsilon_{0}$ и $\varepsilon_{33}^{T} / \varepsilon_{0}$ в зависимости от концентрации $\mathrm{PbTiO}_{3}$. Видно, что амплитуда максимума $\varepsilon / \varepsilon_{0}$ (кривая 4 , не поляризованная керамика) меньше, чем аналогичной зависимости $\varepsilon_{33}^{T} / \varepsilon_{0}$ (кривая 5) для поляризованных керамик, и смещена в сторону ромбоэдрического состава [4]. Интересными являются результаты исследования диэлектрической проницаемости композита ПП $+5 \% \quad \mathrm{PbTiO}_{3}-\mathrm{PbZrO}_{3}$, поляризованной при температуре больше чем температура Кюри (кривая 6). Видно, что композиты, поляризованные при температурах $\geqslant$ чем температура Кюри пьезофазы значение диэлектрической проницаемости больше по амплитуде и максимум ее наблюдается в области тетрагональной структуры. Изменение максимума зависимости $U_{\text {epd }}$ от концентрации $\mathrm{PbTiO}_{3}$ для предварительно плазмокристаллизованных композитов можно связать с увеличением электроотрицательности макромолекул ПП, так как электроотрицательность макромолекул полимерной матрицы, как уже было сказано, приводит к увеличению локальных электрических полей. Заметное увеличение $\delta$ и $\varepsilon$ после плазменной кристаллизации также можно связать с увеличением электроотрицательности макромолекул полимерной матрицы. Таким образом, полученные многочисленные экспериментальные результаты показывают, что электретный эффект в композитах полимер-сегнетопьезокерамики определяется несколькими параметрами пьезофазы, т.е. является многофакторной функцией. Поэтому оптимизация технологии получения композитов является актуальной задачей при разработке многофункциональных активных композитов-электретов, пьезо- и пироэлектриков. Необходимо разработать математическую модель указанных композитов, на основе которых следует оптимизировать отдельные характеристики системы полимер-сегнетопьезокерамика [26-28]. Полученные нами многочисленные экспериментальные результаты показывают, что на изменение межфазных взаимодействий влияет не только электроотрицательность полимерной фазы, осуществленная плазменной кристаллизацией, но и электроотрицательность катионов пьезоэлектрической фазы. Поэтому, были параллельно изучены влияние электроотрицательности катионов пьезофазы на пьезоэлектрические, диэлектрические свойства и электретный заряд композитов. На рис. 5 приведены параметры композитов в зависимости от электроотрицательности элементов $\mathrm{B}^{\prime \prime \prime \prime}$. С увеличением электроотрицательности $\mathrm{B}^{\prime \prime \prime \prime}$ степень ковалентности $\mathrm{B}^{\prime \prime \prime}-\mathrm{O}$ растет. Видно, что с увеличением электротрицательности $B^{\prime \prime \prime \prime}$ монотонно уменьшаются параметры $\left(d_{33}, Q_{r}, \varepsilon_{33}\right)$ композитов. Это, как уже было отмечено выше, непосредственно определяется сопротивляемостью ионизованных при поляризации локальных энергетических уровней квазизапрещенной зоны полимерной фазы к воздействию механических напряжений, т. е. энергией активации нейтрализации полимерных ловушек механическим возмущением. Наряду с концентрацией локальных уровней в квазизапрещенной зоне полимерной фазы необходимо 

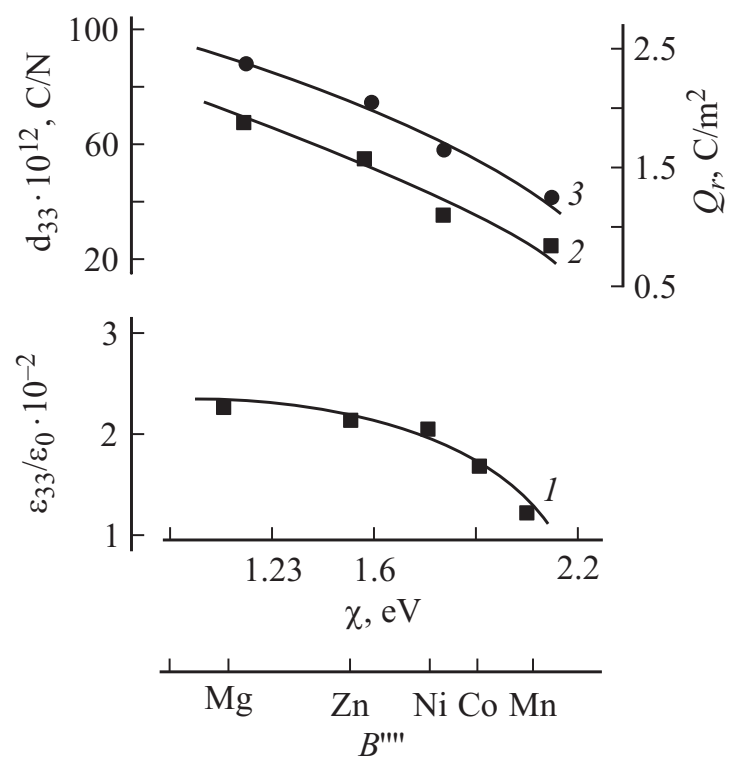

Рис. 5. Изменение параметров композита на основе ПЭВП в зависимости от электроотрицательности $\chi$ катионов - $\mathrm{B}^{\prime \prime \prime \prime}$ пьезофазы $\mathrm{PbTiO}_{3}-\mathrm{PbZrO}_{3}-\mathrm{PbB}_{1-\alpha}^{\prime} \mathrm{B}_{\alpha}^{\prime \prime} \mathrm{O}_{3}-\mathrm{PbB}_{1-\alpha}^{\prime \prime \prime} \mathrm{B}_{\beta}^{\prime \prime \prime} \mathrm{O}_{3}$. $1-\varepsilon_{33} / \varepsilon_{\varepsilon_{0}}$ диэлектрическая проницаемость композита, $\varepsilon_{0}-$ электрическая постоянная $-8.854 \cdot 10^{-12} \Phi / \mathrm{M}$; 2 - электретный заряд $Q_{r}$ композита; $3-d_{33}$ пьезомодуль композита. $E_{\mathrm{pol}}-3.5 \mathrm{MB} / \mathrm{M}, T_{\mathrm{pol}}=393 \mathrm{~K}, t=0.5$ ч.

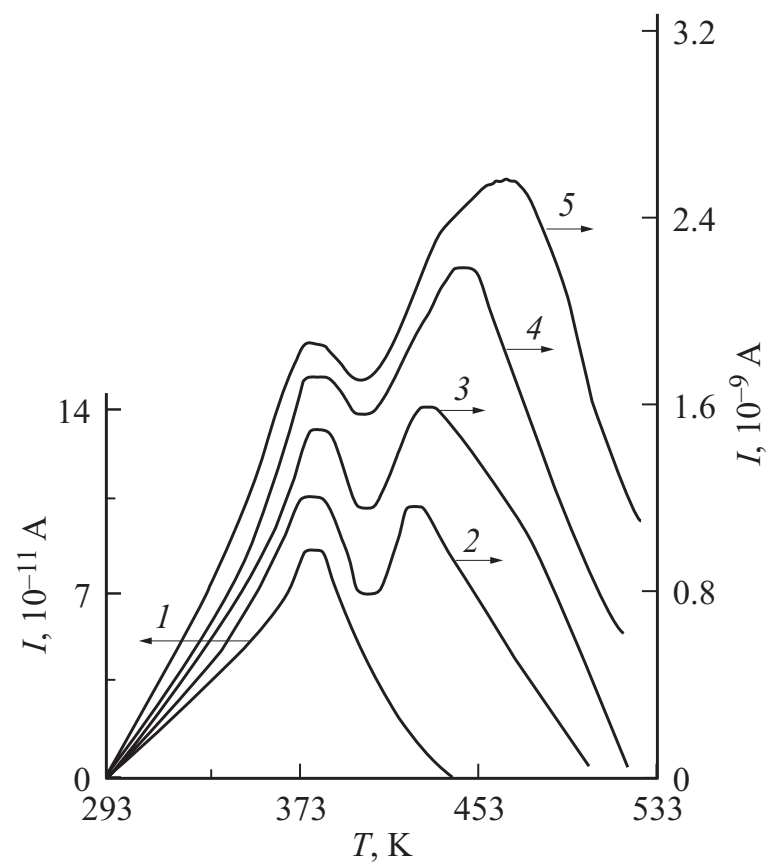

Рис. 6. Спектры термостимулированного деполяризационного тока ПЭВП и композитов: ПЭВП $-\mathrm{PbTiO}_{3}-$ $\mathrm{PbNb}_{2 / 3} \mathrm{Mg}_{1 / 3} \mathrm{O}_{3}-\mathrm{PbN}_{b 2 / 3} \mathrm{~B}^{\prime \prime \prime \prime} \mathrm{O}_{3} .1$ - для ПЭВП; 2 - для композита на основе пьезофазы с катионом $\mathrm{Mn} ; 3$ - для композита на основе пьезофазы с катионом $\mathrm{Ni} ; 4$ - для композита на основе пьезофазы с катионом Zn; 5 - для композита на основе пьезофазы с катионом Mg. Условие поляризации композитов: $E_{\mathrm{pol}}=4.5 \mathrm{MB} / \mathrm{M} ; T_{\mathrm{pol}}=393 \mathrm{~K}, t_{\mathrm{pol}}=0.5$ ч, объемное содержание пьезофазы $\Phi=50 \%$ об. иметь высокую глубину энергетического залегания ловушек. В связи с этим нами были исследованы спектры термостимулированного деполяризационного тока поляризованных пьезокомпозитов. Спектры термостимулированного деполяризационного тока позволяют получить информацию о зарядовом состоянии границы раздела фаз и стабильности граничного заряда $Q_{r}$ в зависимости от электроотрицательности катионов пьезофазы композита. Спектры термостимулированного деполяризационного тока для ПЭВП и композитов ПЭВП $\mathrm{PbTiO}_{3}-\mathrm{PbZrO}_{3}-\mathrm{PbB}_{1-\alpha}^{\prime} \mathrm{B}_{\alpha}^{\prime \prime} \mathrm{O}_{3}-\mathrm{PbB}_{1-\beta}^{\prime \prime \prime}-\mathrm{B}_{\beta}^{\prime \prime \prime} \mathrm{O}_{3}$ приведены на рис. 6. Композиты отличаются электроотрицательностью катионов пьезофазы: $\mathrm{Mn}$ (2,12 эВ), Со (1.84 эВ), Ni (1.56 эВ), Zn (1.32 эВ) и $\mathrm{Mg}$ (1.23 эВ) или степенью ковалентности катион-кислород $\left(\mathrm{B}^{\prime \prime \prime \prime}-\mathrm{O}\right)$, т. е. $\mathrm{Mn}-\mathrm{O}, \mathrm{Co}-\mathrm{O}, \mathrm{Ni}-\mathrm{O}, \mathrm{Zn}-\mathrm{O}$ и $\mathrm{Mg}-\mathrm{O}$. Полагаем, что с увеличением степени ковалентности связи $\mathrm{B}^{\prime \prime \prime \prime}-\mathrm{O}$ заметно уменьшается взаимодействие между полимерными цепями и поверхностью пьезофазы, т. е. уменьшаются межфазные взаимодействия. Это в свою очередь сопровождается увеличением подвижности полимерных цепей в окрестности поверхности пьезокерамических частиц, уменьшается энергия активации зарядов, аккумулированных на границе раздела фаз, ограничивается область полимерной фазы, структура которой формируется под влиянием поверхности пьезочастиц. Указанные факторы очень хорошо отражены в спектрах термостимулированного деполяризационного тока (рис. 6). На основе этих спектров можно сделать вывод о том, что использование в качестве пьезофазы сегнетопьезокерамики с катионами низкой электроотрицательности и ковалентности $\mathrm{B}^{\prime \prime \prime \prime}-\mathrm{O}$ приводит к усилению адсорбционных взаимодействий между полимерной и пьезоэлектрической фазами, сдвигу второго максимума спектра в сторону высоких температур. Растет концентрация центров локализации зарядов на границе раздела фаз, уменьшается подвижность цепей макромолекул полимерной фазы и увеличивается величина энергии активации стабилизированных в процессе поляризации на границе раздела фаз носителей электрических зарядов и, следовательно, локальное поле на пьезочастицах.

Сказанное позволяет в первом приближении построить возможную модель микроструктированной пьезоэлектрической частицей электретных и пьезоэлектрических композитов (рис. 7). Для выявления механизма формирования электретного и пьезоэлектрического эффектов необходимо проанализировать существующие физические модели с целью ее усовершенствования [26-28], учитывая при этом роль электроотрицательности компонентов композита. Как уже было отмечено, электроотрицательность катионов пьезофазы и полимерной матрицы ограничивает подвижность макромолекул, а это в свою очередь требует формирования более тонкого межфазного полимерного слоя с высокой кристаллической структурой (рис. 6). Такая структура композита и граничного слоя способствует более ин- 

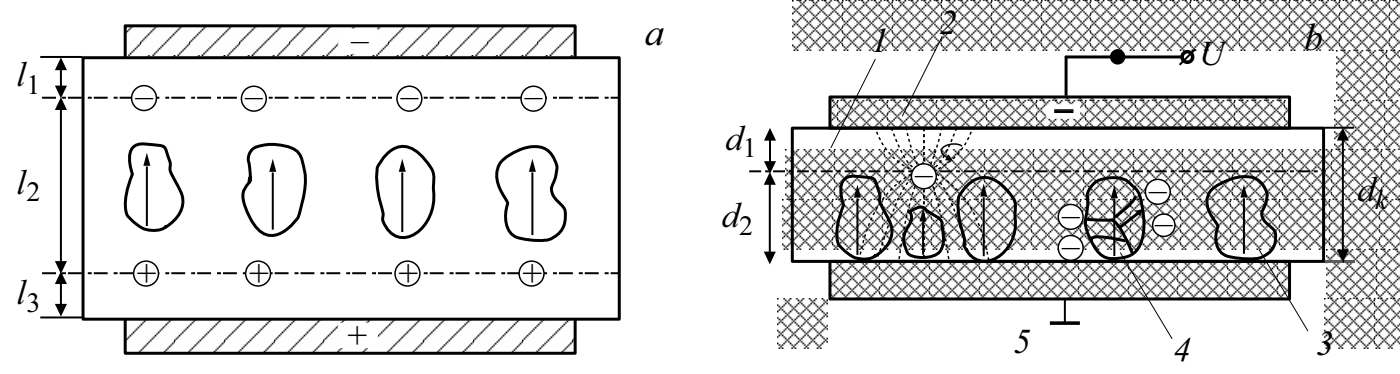

high-voltage electrode

C

a polymer layer whose structure is weakly dependent on die surface interaction of the phases

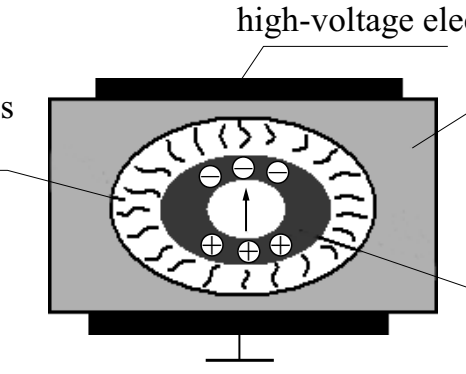

initial polymer layer

a polymeric transition layer, whose structure is mainly determined by the influency

of the surface of the piezo-particles

Рис. 7. Модель поляризации пьезоэлектрической частицы в электретном композите: $a) l_{1}$ и $l_{3}-$ толщина областей, которые находятся в непосредственном контакте с электродом; $l_{2}$ - область, находящаяся в непосредственном контакте с пьезочастицей; b) 1 - полимерный слой, находящийся в непосредственном контакте с электродом; 2 - инжектирующий электрод; 3 - пьезокерамическая частица; 4 - пьезоэлектрическая частица, домены которой не успели ориентироваться по полю поляризации (не эффективная квазинейтральная система); 5 - заземленный электрод. с) модель межфазного слоя в системе полимер-сегнетопьезокерамика.

тенсивному накоплению заряда на границе пьезофазы и полимера.

На рис. 7 предложена возможная картина модели композитного материала, позволяющая в первом приближении объяснить формирование вышеназванных эффектов с учетом электронно-ионных и поляризационных процессов (рис. 7, $a-c$ ). На рис. 7, $a$ показана стилизованная картина формирования квазинейтральной системы ориентированный домен-инжектированный заряд [16], которая позволяет объяснить механизм развития начальной стадии электретного и пьезоэлектрического эффектов. На рис. 7, $b$ показаны возможные электронно-ионные и поляризационные явления в композите полимер-сегнетопьезокерамика в процессе термоэлектретирования. В первую очередь происходит инжекция электронов в композит в условиях одновременного воздействия электрического поля $\left(E_{f}\right)$ и температуры $\left(T_{f}\right)$. Предположим, что заряд стабилизирован в объеме композита на расстоянии $d_{1}$ от поверхности высоковольтного электрода. Видно, что инжектированный заряд стабилизирован в квазизапрещенной зоне полимерной фазы и создает локальное поле, приводящее к ориентации доменов, по направлению вектора напряженности электрического поля поляризации. Именно это поле способствует эффективной поляризации пьезофазы (рис. 7,b). Более интересным с точки зрения эффективной поляризации композита в целом является вероятность образования квазинейтральной системы, состоящей из мигрирующих (инжектированных) зарядов и доменов, не успевших сориентироваться по полю поляризации. Это означает, что этот тип квазинейтральной системы не эффективен и не участвует в формировании электретного и пьезоэлектрического эффектов. Эта задача имеет огромное значение при разработке композитов различных назначений и оптимизации их параметров [26-28]. Здесь необходимо учесть проводимость полимерной матрицы и подвижность доменов пьезоэлектрической фазы композитных материалов. Известно, что проводимость диэлектриков, в том числе и гетерогенных диэлектрических систем, в первом приближении определяется как $\sigma=\mu N e$, где $\mu-$ подвижность и $N$-концентрация носителей заряда, $e-$ заряд электрона. Для нашей задачи необходимо учесть подвижность и величину локального механического напряжения доменов пьезофазы. При определении величины электретного заряда (электретной разности потенциалов) было отмечено, что она существенно зависит от структуры пьезофазы композитов: ромбоэдрической, тетрагональной и гетерогенной (рис. 2) [4]. Известно, что пьезокерамики ромбоэдрической структуры имеют домены бо́льших размеров (5-20 мкм) по сравнению с керамиками тетрагональной структуры (5-10 мкм) [4]. Также известно, что подвижность доменов пьезокерамик тетрагональной структуры (в основном 90-градусных) меньше, чем аналогичного параметра пьезокерамик ромбоэдрической структуры с 109- и 71-градусными доменами. Поэтому необходимо принять во внимание соответствие подвижности доменов пьезофазы с подвижностью 
инжектированных электронов в полимерной фазе в процессе электротермополяризации. Особое значение имеет подвижность электронов и ионов в полимерной фазе, структура которой формировалась под влиянием поверхности пьезочастиц, т.е. в переходном слое (рис. 7,c). Здесь же отмечаем, что определение взаимосвязи между временами релаксации доменов в пьезофазе и инжектированных зарядов в переходном слое требует более тщательного изучения, которое выходит за рамки представленной работы. По нашему мнению, более оптимальным является принятие переходного слоя с кристаллической структурой. В этом случае можно ожидать образование больших по концентрации эффективных квазинейтральных систем, но меньших по эффективности.

\section{4. Заключение}

В результате исследования было установлено следующее.

1) Электроотрицательность пьезофазы и полимерной матрицы играют решающую роль в формировании высокого электретного состояния в композитах.

2) Подвижность доменов пьезофазы и инжектированных электронов в полимерной матрице существенно влияет на формирование эффективной квазинейтральной системы в композитах полимер-сегнетопьезокерамика;

3) Предложена более усовершенствованная модель, объясняющая механизм формирования электретного эффекта.

\section{Список литературы}

[1] И.С. Рез., Ю.М. Поплавко. Диэлектрики. Основные свойства и применения в электронике (М., Радио и связь, 1989).

[2] С.А. Гриднев. Соросовский образовательный журн., № 5, 105 (1997).

[3] М. Лайнс, А. Гласс. Сегнетоэлектрики и родственные им кристалль (М., Мир, 1981).

[4] Е.Г. Фесенко, А.Я. Данцигер, О.Н. Разумовская. Новые пьезоэлектрические материалы (Ростов н/Д., РГУ, 1983).

[5] Г.М. Сеслер. Электреты (М., Мир, 1983).

[6] В.А. Гольдаде, Л.С. Пинчук Эклектретные пластмассы: Физика и материаловедление (Минск, Наука и техника, 1987).

[7] Г.А. Лущейкин. Полимерные электеты (М., Химия, 1984).

[8] М.А. Курбанов, М.К. Керимов, С.Н. Мусаева, Э.А. Керимов. Высокомолекулярные соединения, Б, 48 (10), 1892 (2006).

[9] В.Г Бойцов, Д.А. Рычков. Материаловедение, № 12, 46 (2001).

[10] Л.А. Щербаченко, В.С. Борисов, Н.Т. Максимива, Е.С. Барышников, В.А. Карнаков, С.Д. Марчук, Я.В. Ежова, Л.И. Ружников. ЖТФ, 79 (9), 129 (2009).

[11] А.А. Рычков, А.А Малыгин, С.А. Трифонов, Д.А. Рычков. ЖПХ, 77 (2), 280 (2004).
[12] М.А. Курбанов, И.С. Султанахмедова, Э.А. Керимов, Х.С. Алиев, Г.Г. Алиев, Г.М. Гейдаров. ФТТ, 51 (6), 1154 (2009).

[13] Ю.А. Гороховатский, Г.А. Бордовский. Термоактиващионная токовая спектроскопия высокоомных полупроводников и диэлектриков (М., Наука, 1991).

[14] M.A Kurbanov, A.A. Bayramov, N.A. Safarov, I.S. Sultanakhmedova, S.N. Musaeva. United State Patent, 2012. N US 8, 187, 488 B2.

[15] М.Ф. Галиханов, А.А. Козлов, Е.А. Карабаева, Р.Я. Дебердеев, Д.Э. Темнов, Е.И. Бобрицкая, И.В. Кришталь. Химия и хим. технология, 52 (4), 91 (2009).

[16] M.K. Kerimov, M.A. Kurbanov, A.A. Bayramov, A.I. Mamedov. Matrix Active Micro and Nanocomposites Based on the Polymer, Semiconductive and Ferropiezoceramic Materials. Nanocomposites and Polymers with Analytical Methods / Book 3. Book ed. by John Cuppoletti (INTECH Open Access Publisher, 2011) p. 375.

[17] Р.А. Андриевский, А.В. Рагуля. Наноструктурные материалы (М., Издат. центр „Академия“, 2005).

[18] А.Ю. Беданоков, В.А. Борисов, А.К. Микитаев, Т.О. Керефов, Э.М. Давыдов, М.А. Микитаев, Т.О. Керефов, Э.М. Давыдов, М.А. Микитаев. Пласт. массы, № 4, 48 (2007).

[19] Е.И. Григорьев, С.Н. Завьялов, С.Н. Чвалун. Письма ЖТФ, 30 (8), 40 (2004).

[20] А.И. Гусев. Наноматериалы, структуры и технологии (М., Физматлит, 2009).

[21] С.А. Озерни, Е.В. Киреева, Е.И. Григорьев, Е.Н. Герасимов, С.Н. Чвалун. Высокомолекулярные соединения, А, 49 (7), 1215 (2007).

[22] А.Д. Помогайло, А.С. Розенберг, И.Е. Уфлянд. Наночастицы металлов в полимерах (М., Химия, 2000).

[23] В.Г. Шевченко. Основы физики полимерных композиционных материалов. Учеб. пособие для студентов по специальности „Композиционные наноматериалы“ (М., МГУ, 2010).

[24] М.А. Курбанов. Автореф. канд. дис. (Баку, 1974) 153 с.

[25] М. Щелев. Оптоэлектрон. приборы. Фотоника, 45 (3), 86 (2014).

[26] F.A. Aliev, V.B. Larin. Optimization of linear control systems: analytical methods and computational algorithms (Amsterdam, Gordon and Breach Science Publishers, 1998).

[27] F.A. Aliev, N.A Aliev, K.G. Hasanov, A.P. Guliev, A.K. Turarov, G.V. Isaeva. TWMS. J. Pure and Appl. Math., $6(2), 158$ (2015).

[28] F.A Aliev, V.B. Larin. Appl. Comput. Math., 13 (1), 46 (2014).

Редактор Г.А. Оганесян 
Electret effect in polymer

composites-ferroelectric ceramics with

different electrical negativity polymer matrix and cations piezophase

M.A Kurbanov, I.S. Ramazanova, Z.A. Dadashev, U.V. Yusifova, G.Kh. Huseynova, K.K. Azizova,

I.A. Farajzadeh

Institute of Physics,

National Academy of Sciences of Azerbaijan, AZ-1143 Baku, Azerbaijan

Abstract The influence of electrical negativity phases controlled by crystallization of the composite under the action of an electric discharge plasma and covalent cations piezophase on the mechanism of formation of a stable electret effect. The features of the formation of the electret effect in composites based on polyolefins (HDPE, PP), fluoropolymers (F42) and segnetopezoelectric ceramics family zirconate - lead titanate $\left(\mathrm{Pb}(\mathrm{Zr}, \mathrm{Ti}) \mathrm{O}_{3}\right)$, crystallized under the action of an electric discharge plasma. A physical model of electret composites, taking into account the role of homo- and heterocharge created in the composite by dispersing its piezoceramic particles of different structures rhombohedral, tetragonal, heterogeneous. 